\title{
MANEJO DA ADUBAÇÃO DO ARROZ IRRIGADO EM SISTEMA PRÉ- GERMINADO NA PRODUTIVIDADE E PERDA DE NUTRIENTES ATRAVÉS DA ÁGUA DE DRENAGEM INICIAL
}

\author{
IRRIGATED RICE FERTILIZATION MANAGEMENT ON GRAIN YIELD AND NUTRIENTS LOSS \\ THROUGH INITIAL DRAIN DISCHARGE IN THE PREGERMINATED SYSTEM
}

\author{
Enio Marchezan ${ }^{1}$ Tommi Segabinazzi ${ }^{2}$ Victor Marzari ${ }^{2}$ Silvio Carlos Cazarotto Villa ${ }^{2}$ \\ Luis Antonio de Avila ${ }^{3}$
}

\begin{abstract}
O experimento foi conduzido objetivando avaliar os efeitos de formas de manejo da adubação ( $P$ e K) do arroz irrigado, semeado no sistema pré-germinado, sobre a produtividade do arroz e as perdas de nutrientes através da água de drenagem inicial. Os tratamentos foram: T1-testemunha sem adubação; T2- adubação aos 20 dias antes da semeadura sem incorporação; T3-adubação aos 20 dias antes da semeadura com incorporação do fertilizante; T4- adubação aos 05 dias antes da semeadura sem incorporação; T5- adubação aos 05 dias antes da semeadura com incorporação do fertilizante; T6- aplicação do fertilizante à lanço 10 dias após a semeadura; T7- aplicação do fertilizante à lanço 25 dias após a semeadura. $O$ rendimento de grãos não foi afetado pelos diferentes procedimentos de manejo da adubação. A adubação realizada aos 5 dias antes da semeadura mostrou-se a menos indicada, devido a maior perda de nutrientes, principalmente de potássio. Contudo as perdas verificadas estiveram dentro de limites aceitáveis de acordo com a legislação vigente.
\end{abstract}

Palavras-chave: impacto ambiental, manejo sustentável de várzea, fósforo, potássio.

\section{SUMMARY}

The experiment was conducted aiming to evaluate the effects of fertilization management in the pregerminated system, on grain yield and nutrient loss through early drain discharge.
The treatments were: T1- Control (without fertilization); T2fertilization 20 days before sowing without incorporation; T3fertilization 20 days before sowing with fertilizer incorporation; T4-fertilization 05 days before sowing without incorporation; T5fertilization 05 days before sowing with fertilizer incorporation; T6-fertilizer application 10 days after sowing; T7-fertilizer application 25 days after sowing. Grain yield was not affected by the different fertilization management procedures. The fertilizer applied 05 days before sowing promoted the highest nutrients loss, especially potassium. However, recorded loss values were within the range allowed by current legislation.

Key words: environmental impact, lowland sustainable management, phosphorus, potassium.

O sistema de cultivo pré-germinado de arroz irrigado encontra-se em expansão no Brasil, especialmente no Rio Grande do Sul, como alternativa para controle do arroz vermelho, redução de custos e elevação da produtividade da lavoura. Neste sistema, preconiza-se a semeadura sobre lâmina de água com posterior drenagem para melhor estabelecimento das plântulas. Devido à adubação e à mobilização do solo realizada antes da semeadura e à drenagem da área logo após, ocorre perda de

\footnotetext{
${ }^{1}$ Engenheiro Agrônomo, Doutor, Professor Titular, Departamento de Fitotecnia (DF). Universidade Federal de Santa Maria (UFSM). Bolsista do CNPq. UFSM, Centro de Ciências Rurais (CCR), 97105-900, Santa Maria, RS. E-mail: emarch@ccr.ufsm.br. Autor para correspondência.

${ }^{2}$ Acadêmicos do Curso de Agronomia, CCR, UFSM. Bolsistas do CNPq.

${ }^{3}$ Engenheiro Agrônomo, MSc., Professor Assistente, DF, CCR, UFSM.

Recebido para publicação em 29.08.00. Aprovado em 20.12.00
} 
nutrientes, podendo afetar a sustentabilidade do sistema. Assim, o objetivo deste experimento foi avaliar alternativas de manejo da adubação no sistema pré-germinado quanto à produtividade do arroz irrigado e quanto às perdas de nutrientes através da água de drenagem inicial da lavoura.

O ensaio foi conduzido no ano agrícola de 1999/00, em solo classificado como PLANOSSOLO com as seguintes características: Argila: $24 \%$; $\mathrm{pH}$ $\left(\mathrm{H}_{2} \mathrm{O}\right):$ 5,0: pH (SMP): 5,5; P: 4,0mg.1 ${ }^{-1}$; : 32,0mg..$^{-1}$; MO: 1,6\%. A adubação utilizada foi de $40 \mathrm{Kg} \mathrm{ha}^{-1}$ de $\mathrm{P}_{2} \mathrm{O}_{5}$ e $60 \mathrm{Kg} \mathrm{ha}^{-1}$ de $\mathrm{K}_{2} \mathrm{O}$ na forma de superfosfato triplo e cloreto de potássio, respectivamente. $\mathrm{O}$ preparo foi realizado com o solo seco, utilizando-se uma enxada rotativa. A incorporação dos fertilizantes foi realizada manualmente com enxada no solo alagado. $\mathrm{O}$ delineamento experimental foi de blocos ao acaso, com quatro repetições, com as parcelas medindo $3 \mathrm{~m}$ $\mathrm{x} 4 \mathrm{~m}$, sendo os tratamentos: $\mathrm{T} 1-\mathrm{t}$ testemunha sem adubação; T2- adubação aos 20 dias antes da semeadura em superfície; T3- adubação aos 20 dias antes da semeadura com incorporação do fertilizante; T4- adubação aos 05 dias antes da semeadura em superfície; T5- adubação aos 05 dias antes da semeadura com incorporação do fertilizante; T6- aplicação do fertilizante à lanço 10 dias após a semeadura; T7- aplicação do fertilizante à lanço 25 dias após a semeadura.

A drenagem das parcelas foi realizada aos três dias após a semeadura, com volume correspondente a $1.000 \mathrm{~m}^{3} \mathrm{ha}^{-1}$. Para a coleta das amostras de água de drenagem, foi aberto um pequeno sulco na taipa de cada parcela, sendo coletadas 10 sub-amostras durante a drenagem. As amostras foram acondicionadas em frascos plásticos e congeladas para posterior análise química, realizada no laboratório do Departamento de Solos da Universidade Federal de Santa Maria, de acordo com a metodologia descrita por TEDESCO et al. (1995). Para determinação do fósforo, as amostras foram filtradas com filtro Millibore $0,45 \mu \mathrm{m}$ e clareadas com ácido clorídrico (50\%).

A adubação do arroz irrigado no sistema pré-germinado não afetou o rendimento de grãos (Tabela 1), pois não houve diferença entre a testemunha sem adubação e os demais tratamentos. Em função disso, não se observou efeito das épocas de aplicação nem da incorporação dos fertilizantes sobre o rendimento de grãos. Esta falta de resposta à adubação possivelmente pode ser explicada pela fertilidade natural do solo e pela elevação da disponibilidade de nutrientes após o alagamento do mesmo VAHL (1999).

As perdas de nutrientes através da água de drenagem inicial não foram afetadas pela incorporação ou não do fertilizante, mas apenas pela época de aplicação do mesmo, sendo que aplicação realizada 5 dias antes da semeadura, com ou sem incorporação, proporcionou maiores perdas, especialmente de potássio, que apresentou concentração de $9,55 \mathrm{mg} \ell^{-1}$ na água de drenagem (Tabela 1). Para as maiores perdas de $\mathrm{N}_{-} \mathrm{NH}_{4}$ verificadas nos tratamentos com adubação 10 e 25 dias após a semeadura, comparados com a testemunha, não se dispõem de explicação.

Para $\mathrm{P}$ e $\mathrm{N}$, nutrientes de maior impacto ambiental negativo, as perdas registradas estão abaixo do permitido pela portaria 05/89 da Secretaria de Saúde e do Meio Ambiente (RIO GRANDE DO SUL, 1989), que é de $10 \mathrm{mg} \ell^{-1}$ de N total e $1,0 \mathrm{mg} \ell^{-1}$ de $\mathrm{P}$ total e também de resultados obtidos por WEBER (2000) que encontrou perda de $2,0 \mathrm{Kg}$ de $\mathrm{P}$ por hectare. Autores como DANIEL $\boldsymbol{e t}$ al. (1993) citam que o limite de $\mathrm{P}$ total na água não deveria exceder $0,10 \mathrm{mg} \ell^{-1}$, preconizando a incorporação dos nutrientes para reduzir perdas, enquanto MOLEN et al. (1998) relatam que as perdas aceitáveis de $\mathrm{P}$ situam-se em até $1 \mathrm{~kg} \mathrm{ha}^{-1}$ ano $^{-1}$.

Os procedimentos de manejo da adubação não afetaram significativamente características como número de perfilhos, número de panículas, a qualidade física dos grãos expressa pela quantidade de grãos inteiros e nem o ciclo da cultivar.

A intensidade do preparo da área, o tempo decorrido entre o preparo final do solo e a semeadura e o tipo de solo são fatores que influenciam na quantidade de nutrientes perdidos junto com a água de drenagem inicial. As perdas serão menores se houver poucos nutrientes em suspensão e dissolvidos na água por ocasião da retirada da mesma, devendo-se evitar a aplicação de fertilizantes em momento próximo à semeadura do arroz.

Assim, os procedimentos de manejo da adubação, época e incorporação ou não dos fertilizantes, não afetaram o rendimento de grãos do arroz irrigado e a perda de nutrientes foi influenciada apenas pela época de aplicação dos mesmos, sendo que a adubação realizada 05 dias antes da semeadura, promoveu as maiores perdas, principalmente de potássio. 
Tabela 1 - Rendimento de grãos e quantidade de nutrientes perdidos na água de drenagem sob manejos da adubação mineral em arroz irrigado no sistema pré-germinado. Santa Maria, RS, 2000.

\begin{tabular}{|c|c|c|c|c|c|}
\hline \multirow[t]{2}{*}{ Tratamentos } & \multirow{2}{*}{$\begin{array}{l}\text { Rendimento } \\
\mathrm{Kg} \mathrm{ha}^{-1}\end{array}$} & $\mathrm{~N}-\mathrm{NH}_{4}$ & $\mathrm{~N}-\mathrm{NO}_{3}$ & $\mathrm{P}$ & $\mathrm{K}$ \\
\hline & & \multicolumn{4}{|c|}{$\mathrm{mg} \ell^{-1}$ ou $\mathrm{kg} \mathrm{ha}{ }^{-1}$} \\
\hline Sem adubação & $8.691^{\mathrm{ns}}$ & $1,75 b^{*}$ & 1,08 & $0,10 \mathrm{ab}$ & $2,90 \mathrm{bc}$ \\
\hline Adubação 20 dias antes da semeadura sem incorporação & 7.911 & $2,71 \mathrm{a}$ & $1,31 \mathrm{~cd}$ & $0,09 \mathrm{~b}$ & $4,15 \mathrm{~b}$ \\
\hline Adubação 20 dias antes da semeadura com incorporação & 8.454 & $2,71 \mathrm{a}$ & 1,40 bcd & $0,09 \mathrm{~b}$ & $4,45 \mathrm{~b}$ \\
\hline Adubação 05 dias antes da semeadura sem incorporação & 8.216 & $3,30 \mathrm{a}$ & $1,98 \mathrm{a}$ & $0,13 \mathrm{a}$ & $9,60 \mathrm{a}$ \\
\hline Adubação 05 dias antes da semeadura com incorporação & 8.571 & $3,20 \mathrm{a}$ & $1,94 \mathrm{ab}$ & $0,10 \mathrm{ab}$ & $9,50 \mathrm{a}$ \\
\hline Adubação 10 dias após semeadura sem incorporação & 8.240 & $3,02 \mathrm{a}$ & $1,70 \mathrm{abc}$ & $0,09 \mathrm{~b}$ & $3,05 \mathrm{bc}$ \\
\hline Adubação 25 dias após semeadura sem incorporação & 8.448 & $2,77 \mathrm{a}$ & $1,34 \mathrm{~cd}$ & $0,10 \mathrm{ab}$ & $2,35 \mathrm{c}$ \\
\hline Média & 8.361 & 2,78 & 1,54 & 0,10 & 5,14 \\
\hline $\mathrm{CV}(\%)$ & 6,59 & 18,56 & 22,99 & 19,38 & 18,97 \\
\hline
\end{tabular}

${ }^{\text {ns }}$ Teste F não significativo em nível de $5 \%$ de probalidade de erro.

* Médias não ligadas pela mesma letra na coluna, diferem entre si pelo teste Duncan em nível de 5\% de probalidade de erro.

\section{REFERÊNCIAS BIBLIOGRÁFICAS}

DANIEL, T.C., EDWARDS, D.R., SHARPLEY, A.N. Effect on extractable soil surface phosphorus on runoff water quality. American Society of Agricultural Engineers, Fayeteville, v.36, n.4, p.1079-1085, 1993.

MOLEN, D.T.V.D., BREEUWSMA, A., BOERS, P.C.M. Agricultural nutrient losses to surface water in the Netherlands: impact, strategies, and perspectives. Journal Enviromental Quality, Madison, v.27, p.4-11, 1998.

RIO GRANDE DO SUL. Portaria número 05/89 de 16 de março de 1989-SSMA. Aprova a Norma Técnica que dispõem sobre critérios e efluentes líquidos... Diário Oficial, Porto Alegre, 29 de março de 1989.
TEDESCO, M.J., GIANELlO, C., BISSANI, C.A., et al. Análises de solo, plantas e outros materiais. Porto Alegre : UFRGS, Faculdade de Agronomia, Departamento de Solos, 1995. 174p. (Boletim Técnico de Solos, 5).

VAHL, L.C. Fertilidade de solos de várzea. In: GOMES, S.G., PAULETTO, E.A. Manejo do solo e da água em áreas de várzea. Pelotas : Embrapa Clima Temperado, 1999. Cap.5. p.119-162.

WEBER, L. Consumo e qualidade da água e cultivares de arroz irrigado em diferentes sistemas de cultivo. Santa Maria - RS, 2000. 60p. Dissertação (Mestrado em Agronomia) - Programa de Pós-graduação em Agronomia, Universidade Federal de Santa Maria, 2000.

Ciência Rural, v. 31, n. 5, 2001. 